\title{
Surgical dummy: a surrogate to live animal in teaching Veterinary Surgery
}

\author{
Melaku Tefera \\ College of Veterinary Medicine, Haramaya University. P. O. Box 144 Haramaya Campus. Ethio- \\ pia.251-0914722459, <melaku22@yahoo.com>
}

\begin{abstract}
The objective of this study was to evaluate a non animal teaching model referred as surgical dummy, for teaching surgery, to novice veterinary students. Students' confidence level and experience in surgical practice was evaluated via questionnaire. In addition student observation was done during the practices by the instructor. The results show that students who first practiced using the surgical dummy had better psychomotor and basic surgical skills. Comments made by the students were positive in relation to sensation of tissue during handling rated as natural. Their confidence increased during surgical procedure due to freedom from worry of consequences of surgical errors. Students had the opportunity to practice adlibitum as the dummy was economical and simple to make. The skill gained in the dummy was adaptable to live animal surgery and decreased the use of cadaver or live animal utilization.
\end{abstract}

Keywords: Veterinary surgery, animal welfare, surgical simulator, mannequin, non animal surgery

\section{Introduction}

The ethos of the course veterinary surgery is to install core surgical skills at the very start of a surgeon's training by teaching the correct basic technique. Surgical training in veterinary medicine has evolved rapidly over the past several decades (Bauer and Seim 1992). Catalysts for change include pressure from concerned students and the public to reduce the use of live animals in teaching (Silva, 2007). High student to staff ratio; an overall reduction in faculty time and effort devoted to skills training; reduction in colleges budget mandating reductions in expensive laboratory practices; have reduced students' exposure to common surgical conditions (Melaku Tefera, 2011). In response to these trends, refining, surgery training courses at veterinary schools have received broad attention (Bauer, 1992). Currently, in most veterinary institutions, surgical instruction involves the use of animals, either alive or as cadavers. Many veterinary faculty and students, question the use of live animals for 
teaching surgery. And condemnation of this practice by animal welfare groups has been the focus of considerable public attention (Martinsen, 2005). This concern has also made it more difficult and expensive to procure animals for teaching purposes. To date, institutions teaching surgery have three options: ignore public concerns; use cadavers; or use client-owned animals which are presented for recovery surgery. Fighting public opinion can lead to "bad press" for the institution and a number of legal suits have been filed against schools by students who feel that being forced to use live animals is a violation of their rights (Rollin, 1990 ). Normal live animals either purchased or acquired from shelters or street dogs were used to teach elective surgeries however, the use of such animals is controversial welfare issues and humane concern (Carpenter et al. 1991). The integration of students into clinical surgery on client-owned animals who have been presented to a teaching hospital may be the ideal method of instruction but requires considerably more student contact time and larger faculty numbers than are available at most schools (Jennings, 1986). The advanced type of referral case which is seen at university hospitals is also generally considered to be inappropriate for training the novice surgeon. Cadavers are often used to replace live animal surgery and the success of this alternative has been reported (Bauer, 1992). However, unless a reliable supply of fresh cadavers is available, these bodies usually have to be stored for varying periods of time prior to their use this requires freezer space and thawed tissues are quite abnormal and aesthetically unpleasant. In Ethiopia, the surgical cases admitted to the clinic are very few. A multiple of factors are involved, lack of facilities, owners' awareness about such benevolent donations of cadavers to scientific discipline and the practice of euthanasia are almost nonexistent. A non live animal teaching model is the best option. When this method is used effectively in a curriculum, it is no longer necessary to sacrifice animals for adequate student training. Even though there are some inanimate models currently on the market like mannequin, stitch boards, plastic bones for teaching surgery (Bauer and Seim, 1992), these are made of artificial materials. To create the best quality education, ideally supported by validation of the efficacy of particular educational tools and approaches, while ensuring the safety of animals and that respect for animal life is not engendered by the student. The surgical dummy which uses real tissue was introduced by the author 25 years ago, at the faculty of veterinary medicine Debre-Zeit, Ethiopia. The advantage of this teaching tool was never evaluated. Thus the aim of this study was to test the suitability of this tool for training surgical skill to novice veterinary students. 


\section{Materials and Methods}

This study was undertaken at four veterinary colleges in Ethiopia namely: Debre-Zeit, Wollo, Jigjiga and Haramaya. Four teaching tools namely, virtual surgery in a classroom setting with digital media, live animal and a surgical dummy. Based on the observation and comments from students, comparative advantages and disadvantages of each teaching tool was ranked by the instructor, on a three scale score (- = not good + =good; ++ = very good). And the specific attribute of the surgical dummy were listed into suitable and unsuitable tasks.

A surgical simulator was constructed from wooden board as shown on Figure 1. This board was used for fixing any organ and tissue obtained from abattoirs to be used as surgical simulator here in referred surgical dummy. The organs or tissue such as skin, intestine muscles and any body parts were fixed using $2 \mathrm{~d}$ to $4 \mathrm{~d}$ nail gauges with large nail head. Cadaver method using dead animals: lambs, piglets and calves were also collected from farms that were used for cadaver surgery. Live animals such as dogs, cat, sheep, goats, cattle, horses, donkeys and camels that were brought to the clinic were used to train students on live animal. Virtual surgical DVD was also displayed on surgical procedures to the students' in addition handouts bearing diagrams and photographs were given. Mannequin with fabric was also tried. The following surgical procedures were explained using the four teaching tools: asepsis and antisepsis, suture material selection, surgical instrumentation, suture patterns haemostasis. As well as operations in dehorning extirpation of the eye, nasolabioplasty, tail docking ear cropping tooth extraction, lapartomy, intestinal anastomosis, castration and, penis amputation and the students. At the end of the practice, in order to assess the impact of the various teaching tools, translatability of skill from dummy to live animal, and student prerception and attitude towards dummy, a questionnaire survey was administered to 114 students from Jigjiga, Wollo and Haramaya universities, on five scale $(1=$ strongly disagree; $2=$ disagree; $3=$ neutral; $4=$ agree; and $5=$ strongly agree), one being the lowest or poorest learning experience and 5 being the highest or best learning experience. Descriptive statistics was made using Microsoft EXCEL software. 


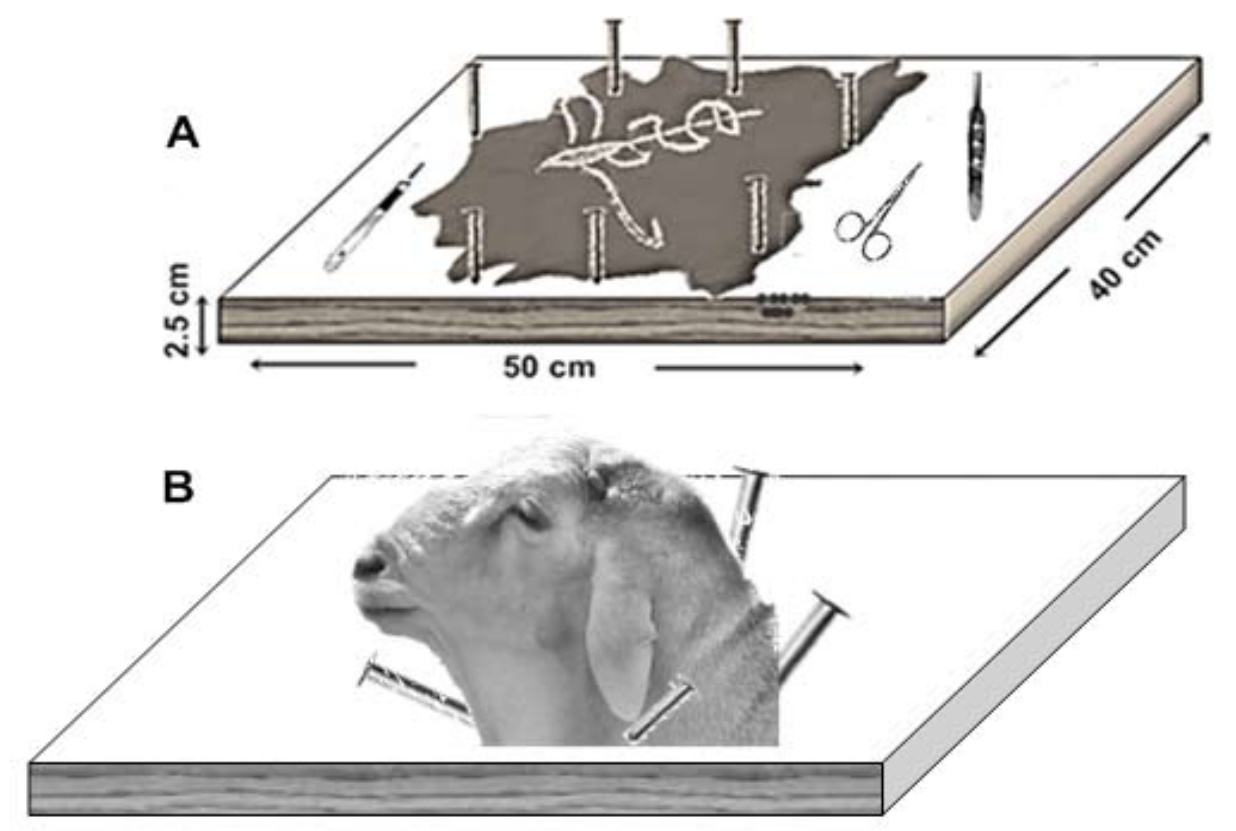

Figur1: The surgical dummy ready for skin (A) and head (B) surgeries

\section{Results}

Our results suggest that the use of surgical dummy; provide training comparable to that provided in a conventional live animal surgery. Albeit the design of the surgical dummy which was morphologically unrelated to animals, the tissues, organs and body parts used were mimicking natural animal tissue. Hence it served like an analogous surrogate for translating surgical skill from laboratory to live animal as shown on Figure 2. Because the tissue was real, the feel or sensation during handling and manipulation of tissue was perfectly simulated. According to our observation the suitability of the surgical dummy for training veterinary surgery and some of its inconvenience are listed on Table 1. And the comparative advantage of the surgical dummy to other simulators is shown on Table 2.

Questionnaire results on students' perception and attitude towards surgical dummy are summarized in Figure 3 and 4. All students responded positive. The dummy enabled them to improve their surgical skill and each and every student had the opportunity to practice compared to only $9 \%$ of students had the opportunity to practice during cadaver or live animal surgery. During such 
surgeries $91 \%$ of the students were mere observers and they had no chance to develop motor skills.

Table 1. A Learners' task which could be performed on surgical dummy

\begin{tabular}{ll}
\hline Suitable & Not suitable \\
\hline Skin suture & Anesthetic monitoring \\
Hollow organ suture & Homeostasis \\
Muscle suture & Fluid therapy \\
Organ incision and suture & Inhalation anesthetic \\
Asepsis and antisepsis & Local anesthetic injection \\
Drug injection & Presurgical patient evaluation \\
Tissue handling & Surgical and Post surgical patient evaluation \\
Incision & Wound healing \\
& Laparatomy \\
& Tohoracotomy \\
\hline
\end{tabular}

Table 2. Comparative advantage of surgical dummy to other simulators

\begin{tabular}{lcccc}
\hline Teaching model & Virtual surgery & Dummy & Cadaver & Live animal \\
\hline Motor skill & - & ++ & ++ & ++ \\
Cognitive skill & ++ & ++ & ++ & ++ \\
Price & ++ & ++ & + & + \\
Humane & + & + & - & - \\
Availability & ++ & ++ & - & - \\
Reusability & ++ & ++ & - & - \\
Take away exercise & ++ & + & - & - \\
Cleaning & ++ & + & - & - \\
\hline
\end{tabular}

(- = not good +=good; ++= very good) 


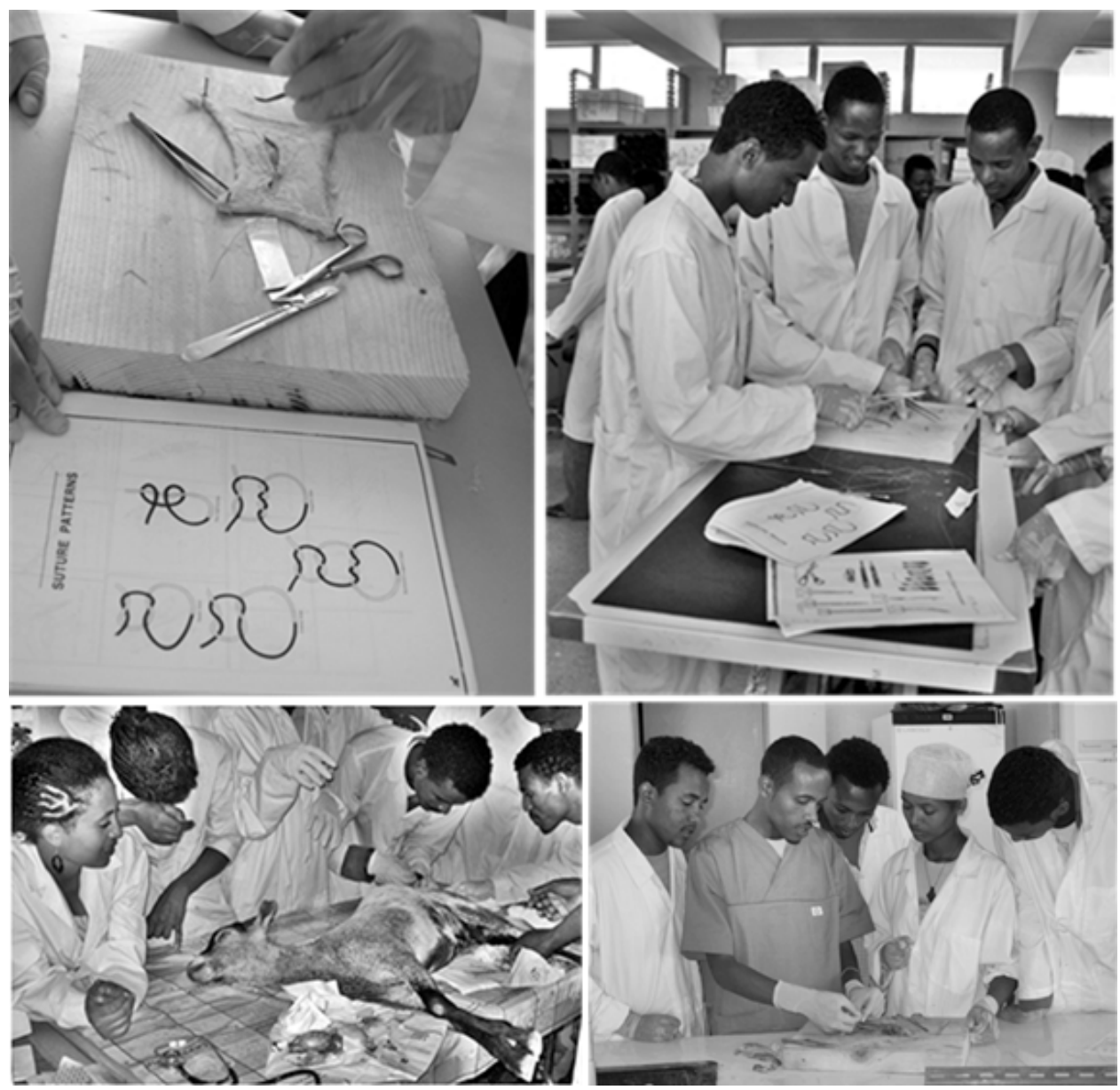

Figure 2. Students translating skilled learned from dummy in to live animal 


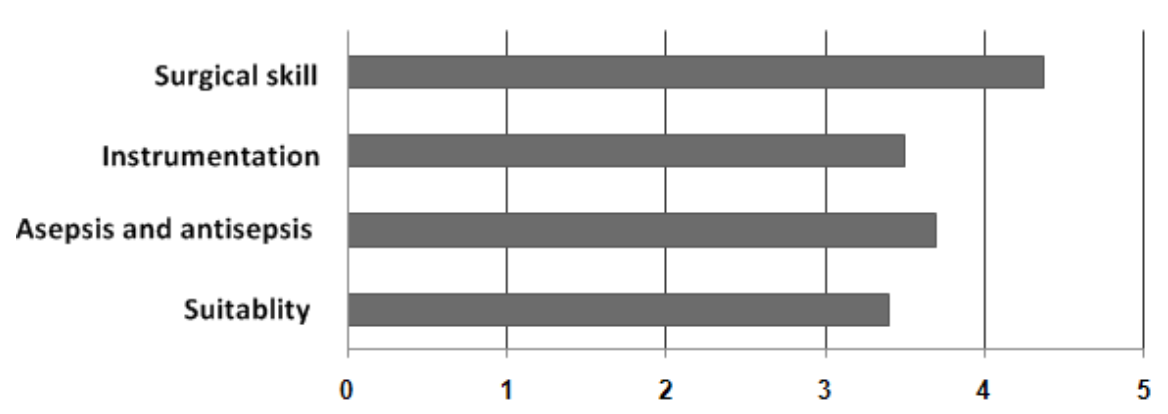

Figure 3. Mean score of students' response on learning objectives ( $1=$ strongly disagree; $2=$ disagree; $3=$ neutral; $4=$ agree; and $5=$ strongly agree)

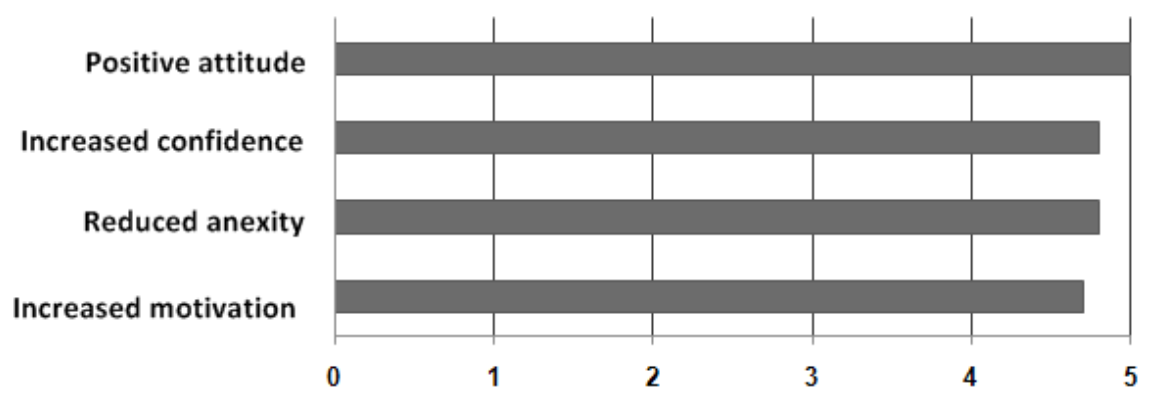

Figure 4. Mean score students' response on importance and perceptions to word dummy (1=strongly disagree; $2=$ disagree; $3=$ neutral; $4=$ agree; and $5=$ strongly agree)

It is our opinion and that of the students' self-confidence was greatly increased after working with the dummy motor skills and comprehension as well. The students renamed the surgical dummy as "The Magic Board" realizing its vast importance.

\section{Discussion}

In order to promote high quality, safe care of surgical patients, the surgical curriculum specifies parameters of knowledge, clinical skills, technical skills, professional behavior and leadership skills and attitudes that are considered necessary to ensure patient safety. It is appropriate for a novice surgeon early exposure to skills training using surgical simulators ensuring that basic skills were mastered before students were exposed to live animal and cadaver practice. Practicing surgical skills on an inanimate model, rather than a live 
animal, helped reduce student apprehension by minimizing the consequences of faulty technique.

Cadavers were used in the teaching elsewhere (Bauer, et al. 1992). In Ethiopia dog and cat cadaver is difficult to get as most owners' wish their pets dies a natural death and there is no practice of euthanasia at all. The cadaver teaching model was not suitable for anesthesia and patient monitoring. It requires cold chain to keep the cadaver. The surgical dummy like the cadaver was not suitable to teach anesthesia fluid therapy and patient monitoring and post operative care and homeostasis. However, it was very good to induce novice surgeons to the start of surgery. Such as: suturing, incision and antisepsis. Instead of whole cadaver individual regions or organs can be mounted and fixed on the dummy and the consistency of the tissue is real.

Non-animal alternatives are available for developing the student's psychomotor skills and teaching ligation of blood vessels (Bauer, 1992). There are also artificial skin models available for practicing suturing, and plastic bones for teaching orthopedics (Johnson, 1990; DeYoung, 1987). There has not been a nonanimal model in general use for teaching the principles of abdominal surgery. Stitch boards use artificial material instead of actual tissue, the materials differ in consistency from actual tissues. Thus mimic less than the surgical dummy. Multimedia are good teaching tools for virtual surgery, however real manipulative skills are not gained. But cognition on asepsis, anesthesia and fluid therapy interactive simulated conditions can be created. Handout and books are also good. But nothing is comparable to the real surgical cases. The use of surgical dummy will supplement the skill.

In veterinary schools in the United States and Canada $69 \%$ of small animals were euthanatized prior to recovery from anesthesia. In $20 \%$ of the schools large animals were euthanatized prior to recovery from anesthesia. In $88 \%$ of the schools cadavers, models, or both were used in at least 1 laboratory session in their surgery training program (Bauer, 1993). An important element of the veterinarian's role will always be to protect animals a parallel to the physician's imperative, premium non nocere (first, do no harm). But cases still does involve, animals' are being killed for dissection .Some argue the ultimate goal of the practice by the student is to save more lives in the future and sacrificing few animals was acceptable. However, there are other ways of fulfilling these aims and delivering a good scientific education that provides the student with the skills, knowledge, and understanding required for the veterinary profession. Moreover, scientific knowledge and clinical skills are 
not all that are required of veterinarians. As professionals, veterinarians must understand animal behavior and appreciate all the aspects of pain and emotion that lead to animal distress. Such challenges require a well-developed sense of compassion, to reduce the harmful use of animals.

In conclusion, we consider the surgical dummy to be an effective and less stressful method of preparing students for students for live animal surgery. Its use has reduced the need for animals in teaching surgery. This follows the philosophical trend of today's society in its demands for non-living teaching models. We suggest the use of a surgical surrogate as an aesthetically acceptable alternative to live animal or cadaver surgery for some introductory surgical laboratories.

\section{References}

Bauer, M. S., Glickman, N., Glickman, L., Toombs, J.P, and Bill P., 1992. Evaluation of the effectiveness of a cadaver laboratory during a 4th-year veterinary surgery rotation. J. Vet. Med. Educ. 19:77-84

Bauer, M.S., and Seim, H.B., 1992. Alternative methods to teach veterinary surgery. Humane Innovations and Alternatives 6:401-404

Bauer, M.S., 1993. A survey of the use of live animals, cadavers, inanimate models, and computers in teaching veterinary surgery. JVME. 203(7):1047-51

Carpenter, L.G, Piermattei, D.L., Salman, M.D., Orton, E.C., Nelson, A.W., Smeak, D.D., Jennings, P.B., and Taylor, R.A., 1991. A comparison of surgical training with live anesthetized dogs and cadavers. Vet Surg. 20(6):373-8.

DeYoung, D.J. and Richardson, D.C. 1987. Teaching the principles of internal fixation of fractures with plastic bone models. JVME .14: 30-31

Greenfield, C.L, Johnson A.L, Arends M.W., and Wroblewski, A.J., 1993. Development of parenchymal abdominal organ models for use in teaching veterinary soft tissue surgery. Vet Surg. 22(5):357-62

Holmberg, D.L., Cockshutt. J.R., and Basher, A.W.P. 1993. Use of a dog abdominal surrogate for teaching surgery. JVME .20: 107-111

Jennings, P.B.1986. Alternative to the use of living animals in the student surgery laboratory. JVME.13:14-16

Ethiop. Vet. J., 2011, 15(2), 1-10 
Johnson, A, L., and Farmer J.A. 1989. Evaluation of traditional and alternative models in psychomotor laboratories for veterinary surgery. JVME. 16:11-14

Johnson A.L., Harai J., Lincoln J., Farmer J.A. and Korvick D. 1990. Bone models of pathological conditions used for teaching veterinary orthopedic surgery. JVME. $17: 13-15$,

Martinsen S. and Jukes N. 2005. Towards a humane veterinary education. JVME. 32(4): 454-460

Rollin BE.1990. Changing social ethics on animals and veterinary medical education. JVME. 17:117-84

Silva R.G., Matera J.M. and Riberio.2007.New alternative methods to teach surgical techniques for veterinary medicine students despite the absence of living animal: is that an academic paradox. Anat. Histol. Embryol.36: 220-224. Doi:10.1111/j.14390264.2006.00759.x

Tefera M. 2010.Global crisis and the challenge of veterinary teaching in Ethiopia. Global Veterinaria. 5(6):294-301 